\title{
Espaço público e ativismo em rede: o caso Maka Angola
}

Espace public et militantisme dans les réseaux : le cas Maka en Angola

Public space and network activism : the case Maka Angola

\section{Cássia Ayres e Isabel Babo}

\section{OpenEdition}

\section{Edição electrónica}

URL: https://journals.openedition.org/ctd/664

DOI: $10.4000 /$ ctd. 664

ISSN: 2491-1437

\section{Editora}

Chaire Unesco Pratiques émergentes en technologies et communication pour le développement

\section{Refêrencia eletrónica}

Cássia Ayres et Isabel Babo, « Espaço público e ativismo em rede: o caso Maka Angola »,

Communication, technologies et développement [En ligne], 6 | 2018, mis en ligne le 18 décembre 2018 consulté le 21 septembre 2021. URL : http://journals.openedition.org/ctd/664 ; DOI : https://doi.org/ $10.4000 /$ ctd. 664

Este documento foi criado de forma automática no dia 21 setembro 2021.

Communication, technologies et développement 


\title{
Espaço público e ativismo em rede: o caso Maka Angola
}

\author{
Espace public et militantisme dans les réseaux : le cas Maka en Angola \\ Public space and network activism : the case Maka Angola
}

Cássia Ayres e Isabel Babo

\section{Introdução}

1 Os meios de comunicação e o jornalismo independente, a liberdade de informação e o debate público de ideias são elementos fundacionais tanto da opinião pública quanto da democracia. O próprio conceito de espaço público incorpora em si a atividade comunicacional, o princípio da publicidade crítica, a pluralidade de opiniões e a formação de públicos que serão tanto mais participativos quanto exprimirem livremente as suas opiniões, se mobilizarem e associarem. Nessa medida, os meios de comunicação constituem um meio de criação de públicos, que discutem ideias e problemas e participam do processo democrático. É assim que, no contexto das novas dinâmicas comunicacionais, os novos dispositivos e tecnologias da informação e da comunicação e os novos formatos digitais têm favorecido a participação de grupos social e economicamente marginalizados, que discutem problemas sociais que lhes dizem respeito ou que os afetam de acordo com as suas próprias perspetivas (Castells, 2000).

2 Ora, a disponibilidade da informação no contexto do jornalismo online de caráter investigativo detém, de acordo com Natalie Fenton (2010), uma contribuição fundamental para fomentar processos cidadãos e participativos que, por sua vez, contribuem para revitalizar espaços públicos mediatizados. Também Castells (2007) defendeu que os meios digitais têm criado novos espaços públicos de participação e deliberação dos cidadãos. Para o autor, é nestes espaços públicos que nascem novas práticas de comunicação e expressão que alteram as configurações sociais relativas à organização dos indivíduos e dos seus pares e destes com as instituições formalmente constituídas. Os média digitais acabam, desse modo, por jogar um papel na formação de um contrapoder. Podem, assim, 
formar-se novas configurações comunicacionais em torno dos média digitais e emergir contrapoderes constituídos por vozes marginalizadas que, por sua vez, desencadeiam consequências que podem criar condições para alterações sociais de cariz democrático.

Este uso dos média digitais é considerado, por isso, um meio relevante para estimular a disseminação de opiniões e a reflexão por parte dos indivíduos utilizadores, assim como para a publicitação das ideias destes em meios alternativos ao mainstream da informação, erigindo espaços alternativos nos quais a forma de um ativismo em rede mais participativo pode manifestar-se (Atton, 2002; Waltz, 2005). Nas redes, com efeito, irrompe uma nova condição humana determinada pela conectividade (dispositivos de conexão, fluxos de informações, bancos de dados, etc.), como observou Massimo Di Felice (2012, 2013a, 2013b), desenvolvendo-se, com o uso das tecnologias digitais em rede por netativistas, formas comunicativas que permitem novas formas de ação e novos processos de ativismo.

4 Destas dinâmicas de utilização alternativa dos meios digitais e do ativismo em rede, onde vozes marginalizadas ganham expressão e se tornam ouvidas, já emergiram iniciativas como Opendemocracy.net, Indymedia.org, Anonymous (anonofficial.com) e, mais recentemente, U-report.in. Esta última surgiu no Uganda, num contexto de escassas oportunidades para a emergência de vozes de grupos vulneráveis, e é uma plataforma digital que permite aos cidadãos mais jovens encontrarem espaço para as suas opiniões e para deliberar sobre questões sociais que lhes dizem respeito. Precedendo este caso no Uganda, em Angola, onde há limitada liberdade de expressão da imprensa e dos cidadãos, emergiu uma plataforma de comunicação digital designada Maka Angola (makaangola.org) que advoga lutar pela democracia e contra a corrupção, que utiliza a denúncia de problemas sociais e encoraja a expressão dos indivíduos em torno de temas e problemas que lhes dizem respeito. Esta plataforma surgiu em 2009, no contexto de um país com quarenta e dois anos de independência e emancipação do colonialismo, que tem sido palco de sucessivas repressões a tentativas de expressão crítica e de livre associação por parte de um regime ou de um partido, o Movimento Popular para a Libertação de Angola (MPLA), que o governa há mais quatro décadas ${ }^{1}$.

5 Para citar alguns exemplos que ilustram a repressão e a violência e que caracterizam a intimidação exercida pelo Estado angolano contra jornalistas e contra cidadãos que protestam, refiram-se : o assassinato de dez jornalistas angolanos, desde 1992, por se terem exprimido contra o regime (The Guardian, 2015; Amnesty International, 2016²); a prisão sumária, em Junho de 2015, de quinze ativistas que se reuniram para ler o livro From Dictatorship to Democracy, do académico norte-americano Gene Sharp, que analisa formas de protesto não-violentas; a condenação do jornalista investigador Rafael Marques de Morais, em 2015, acusado de calúnia no seu livro Diamantes de Sangue, em que relata a violação dos direitos humanos e a corrupção na indústria mineira angolana.

É, portanto, no seio de uma discussão acerca do papel dos média digitais para a construção de espaços públicos plurais e alternativos que facultam o exercício de uma participação democrática, que a plataforma Maka Angola constitui um caso de estudo. Admitimos, também, que o rumo da análise poderia trilhar o caminho daquilo que se convencionou designar como jornalismo colaborativo ou participativo, embora, não obstante, o ponto de vista que aqui adoptamos é o da instauração de um espaço público por meio dos media digitais e de um ativismo em rede. Propomos, por isso, as seguintes questões : Requer o espaço público mediatizado, para existir, condições democráticas ? Quais seriam essas condições, aplicadas ao contexto angolano? Ou, ao invés, pode a 
emergência de um espaço público mediático alternativo, que escapa ao poder político instituído, ter repercussões democráticas ? Como contribui a plataforma Maka Angola, que utiliza os média digitais, para criar essas condições ou esses efeitos no contexto angolano?

Para este estudo da plataforma digital Maka Angola na óptica do espaço público e da utilização dos média digitais, começaremos por uma reflexão sobre o Espaço Público na sua relação com os meios de comunicação e a democracia, para, de seguida, explorar as novas formas e expressões de envolvimento dos cidadãos ao nível das novas modalidades de comunicação e ação mediáticas, como o ativismo em rede ou netativismo. Isto permitirá uma análise da Maka Angola segundo a perspetiva da instauração de um espaço público de expressão por parte de utilizadores-receptores que intervêm e manifestam opiniões, logo, com características democráticas. Esta reflexão irá desembocar na interrogação da ação da Maka Angola em relação ao netativismo e média alternativos, e o seu contributo para a visibilidade, voz e empoderamento de cidadãos.

\section{Espaço público e democracia}

8 Os países que, durante o século XX, viveram processos de independência e emancipação do colonialismo, somados àqueles que emergiram de sistemas económicos socialistas, fizeram recrudescer o debate em torno da noção de espaço público e do surgimento de espaços públicos diversificados onde se verifica a inclusão de cidadãos provenientes de franjas sociais plurais, exteriores às elites políticas, sociais e culturais (Silveirinha, 2004 ; Fraser, 1990). Este debate desenvolve-se em torno da perspetiva da existência de espaços públicos plurais e concorrentes, com discussões críticas produzidas por esses grupos sociais que Fraser (1990 : 120) denominou de "contra-públicos" ou "públicos subalternos".

Ora, a irrupção destes públicos subalternos na esfera pública, ou a concorrência de esferas públicas paralelas em relação ao espaço público dominante, constitui uma outra concepção que problematiza o modelo de espaço público burguês concebido por Jürgen Habermas (1962), no seu estudo sobre a génese da esfera moderna da comunicação. Para Habermas (1986 [1962]), o espaço público é a instância mediadora entre a sociedade civil e o Estado, entre os cidadãos e o poder político-administrativo, sendo o lugar de uma comunicação democrática e dos meios de comunicação social. 0 espaço público é a esfera do uso público da razão argumentativa, onde são discutidas as questões práticas e políticas, e no qual se formam a opinião pública e a vontade política. Ora, Habermas denuncia um alargamento e subsequente fragmentação da esfera pública, durante a segunda metade do século XX, graças aos média de massa e a novos fenómenos de fabricação das opiniões (relações públicas, publicidade comercial, indústrias culturais) que vieram subverter o princípio da publicidade, que é um princípio normativo que estrutura o espaço público entendido como lugar de discussão racional e de formação da opinião pública. Porém, Habermas $(1988,1992)$ vem retificar a posição por si defendida na obra Espaço Público (1962), admitindo que os públicos de massa também resistem à sua vassalização ${ }^{3}$.

10 O declínio do modelo burguês convive com o surgimento de uma multiplicidade de espaços públicos que diversificam a formação de opiniões. Habermas (1992) reconhece, por um lado, que há desde o início uma pluralidade de esferas graças à exclusão de outros grupos: 
11 “A exclusão das camadas inferiores, mobilizadas cultural e politicamente, provoca já uma pluralização da esfera pública na sua fase de formação. Ao lado da esfera pública hegemónica, e entrelaçada nela, forma-se uma esfera pública plebeia" (Habermas, 1992 :165).

12 Por outro lado, considera que, à figura unitária do espaço público, se substitui uma rede de espaços públicos plurais, em torno de associações ${ }^{4}$, fóruns, palcos ou arenas, enquanto assembleias de participantes e lugares de produção discursiva e difusão de sentidos e opiniões.

“As tecnologias de comunicação - a tipografia e a imprensa, a rádio, a televisão, a internet - permitem difundir qualquer enunciação em quase todos os contextos possíveis e ajudam a criar uma rede altamente diferenciada de esferas públicas locais e inter-regionais, literárias, científicas e políticas, internas aos partidos e às associações, mediáticas ou subculturais. Os espaços públicos institucionalizam os processos de formação da opinião e da vontade (...) As suas fronteiras são permeáveis; com efeito, por mais fechado que seja, todo o espaço público permanece porém aberto a outros espaços públicos. (...) todos os espaços públicos parciais remetem para um espaço público global, no qual a sociedade no seu conjunto desenvolve um conhecimento dela própria" (Habermas, 1988 : 425-426).

Estes espaços públicos parciais, inacabados, que se cruzam-se entre si e interpenetram, na perspetiva de Habermas, remetem para um espaço público político global, o que expressa a conservação, no pensamento do autor, de um modelo normativo e universalizável a par de um quadro plural.

Porém, as críticas ao modelo burguês do espaço público não se fizeram sentir somente a partir das novas modalidades associativas e comunicacionais e, mais recentemente, a partir dos novos dispositivos, particularmente do uso generalizado das redes digitais. Autores como Nancy Fraser $(1990,2003)$, a partir da historiografia contemporânea, denunciam o modelo burguês do espaço público que assentou em exclusões de género e em exclusões assentes nos processos de formação das classes sociais - as mulheres, as camadas plebeias e a classe trabalhadora, as minorias étnicas e populares ficaram arredadas da esfera pública - tal como demonstraram que exclusões e conflitos o marcaram sempre. Nessa medida, Fraser $(1990,2003)$ identificou a existência de espaços públicos concorrentes, não liberais e não burgueses, e alternativos (afro-americanos, por exemplo) e "contra-públicos concorrentes" (públicos nacionalistas, públicos dos pequenos camponeses, públicos das mulheres da elite, públicos da classe trabalhadora operária), que contestaram as normas do espaço público burguês, elaborando novos estilos de comportamento político e novas normas de discussão pública e participação na democratização da sociedade. Daqui emergem novas vozes, estando os espaços públicos plurais e inclusivos associados a sociedades mais democráticas.

Fraser (1990 :77) argumenta que a noção de espaço público já "não é adequada aos limites da verdadeira democracia existente nas sociedades capitalistas tardias, requerendo uma nova concepção pós-burguesa do espaço público". A precarização das relações de trabalho e o agravamento das condições socioeconómicas acentuaram as desigualdades sociais da sociedade burguesa e o processo de polarização dos extratos sociais tornou visível a emergência de públicos plurais (Fraser, 1990). Para além da Europa, a participação de públicos plurais tornou-se, igualmente, um fenómeno emergente nas colónias emancipadas na segunda metade do século XX. Como Fraser (1990) considera, citando explicitamente o caso do continente africano, o modelo do espaço público de Habermas não permanecia realizável, porque essa esfera não servia como teoria crítica nem se 
aplicava a outras geografias e épocas e outros públicos. Por sua vez, uma concepção pósburguesa do espaço público (Fraser, 2003) permite pensar espaços públicos plurais, assim como a proliferação de uma multiplicidade de públicos concorrentes e alternativos (os membros dos grupos sociais subordinados - mulheres, operários, negros, homossexuais, etc. - provaram que era vantajoso constituir públicos alternativos) e "contra-públicos subalternos", que constituem arenas discursivas paralelas nas quais membros dos grupos sociais subordinados elaboram e difundem contra-discursos, que lhes permitem difundir a sua própria interpretação das suas identidades, dos seus interesses e necessidades (Fraser, 2003 :119). Nessa medida, o espaço público pós-burguês, orientado para o exercício da democracia, incorpora a ideia de uma pluralidade de públicos - "públicos fortes", "públicos fracos" e "híbridos"- e de formas como estes públicos coexistem entre si, que podem ser alternativas ao domínio do poder pelas elites. No espaço público emergem públicos plurais e desiguais, que se colocam numa relação contestatária em relação ao público dominante.

Com a irrupção de públicos plurais e concorrentes, e com as novas possibilidades comunicacionais que as novas tecnologias de comunicação e informação favorecem, surgem condições de existência de espaços públicos mediatizados que intervêm em processos de democratização. Fenton (2010) identifica que o papel da comunicação na constituição e na manutenção das democracias mais recentes tem sido revigorado através dos novos média e de novas interações de carácter coletivo, com maior liberdade de expressão, associação e imprensa. Isto possibilita a construção de identidades plurais, com gradual emancipação, e de processos de legitimação. Ora, é a partir desta perspetiva inclusiva, onde se reconhece o fracasso dos "velhos média", ou dos média de massa, em concretizarem o ideal democrático de participação plural dos públicos, que a internet e os "novos média" digitais abrem "novas dimensões do espaço público" (Silveirinha, 2004 :251), geradas pelas relações mediatizadas e pelos novos média que estão a "dar a origem às novas teses sobre um acesso, a estes públicos diversos, muito mais democrático".

Os média digitais e a pluralidade dos públicos engendram condições de intervenção política e de democratização da comunicação e, como resultado, instauram novas dinâmicas e fluxos de circulação da informação, das opiniões e das vozes. Criam-se, assim, possibilidades de liberdade de expressão e de jornalismo, e dos cidadãos participarem nos debates públicos e políticos. São condições e consequências destas que se aplicam ao caso da plataforma digital Maka Angola, como veremos de seguida.

\section{A Maka Angola}

Maka Angola é uma plataforma digital de comunicação que foi criada em 2009 pelo jornalista angolano Rafael Marques de Morais. O seu surgimento na sociedade angolana, como plataforma independente e alternativa, relaciona-se com os obstáculos colocados pelo poder político à plena liberdade de expressão, quer ao nível da imprensa quer ao nível das manifestações públicas. Ou seja, a carência de um espaço público livre de debate e de discussão pública de ideias, e de uma imprensa e outros média livres e autónomos do poder político, fez com que esse espaço tenha irrompido nas redes sociais digitais, escapando ao controle estatal. A Maka, como é conhecida pelos seus usuários, centra-se na investigação de factos sobre corrupção e violação dos direitos humanos e na subsequente análise e divulgação destes sob a forma de artigos jornalísticos em dois 
idiomas, português e inglês. Refira-se que os sucessivos abusos contra os direitos humanos perpetrados pelo Estado angolano e os episódios de corrupção que não figuram na agenda da imprensa nacional e não são publicamente denunciados acabam também por não ser citados e objeto de notícia na imprensa internacional. É sobre esta impossibilidade de um princípio de publicidade livre que a plataforma advoga contribuir para o debate público através da divulgação desses temas, estando também disponível no Facebook, Twitter, Youtube e Instagram. Na sua apresentação, fica esclarecido :

“O Maka Angola é uma iniciativa dedicada à luta contra a corrupção e à defesa da democracia em Angola, fundada e dirigida pelo jornalista Rafael Marques de Morais. Maka é um substantivo em Kimbundu [que significa "problema delicado, complexo ou grave"].

19 Angola é dotada de imensuráveis riquezas naturais e tem registado na última década um impressionante crescimento económico, sem impacto positivo no quotidiano da maioria dos angolanos, que continuam a viver na miséria. Esta é a maka!

A maka é de todos, colabore ! Escreva para o Maka Angola"5.

O website Maka Angola (https://www.makaangola.org/) assume-se em defesa da democracia e contra a corrupção. Habitualmente os seus conteúdo são aqueles que não são difundidos na imprensa tradicional por questões que se ligam à falta de liberdade de imprensa, pretendendo o jornalista, através desses canais digitais, informar e suscitar discussões.

Para que cidadãos angolanos, que vivem no território ou na diáspora, e estrangeiros possam colaborar com informações úteis ao processo de investigação liderado por Rafael Marques, a plataforma dispõe de um sistema de segurança que permite o anonimato. 0 site foi, ainda, desenhado e auditado por entidades que trabalham com outros meios de notícias online independentes e com organizações de direitos humanos que operam em regimes repressivos, para evitar que acessos não autorizados aconteçam ao website. A MakaLeaks é a plataforma colaborativa de denúncia (com carácter de Whistleblower), executada no Globaleaks, um software que permite uma plataforma anónima, para qualquer pessoa no mundo, resistente à censura ${ }^{6}$.

Em termos de repercussões ao nível da recepção, em Novembro de 2018, a Maka Angola possuía 328530 seguidores no Facebook e no Youtube alguns de seus vídeos chegaram a obter mais de 29 mil visualizações. No Twitter, a sua ferramenta mais recente, alcançou os 13 mil seguidores. Estes média digitais congregam comentários com conteúdos divergentes e discussões entre receptores-leitores-emissores, além de manifestações de gostos, aprovações, desaprovações e partilhas. Um exemplo de interações promovidas pela plataforma foi o inquérito realizado antes das eleições presidenciais, em 2017, em que o site buscou averiguar a opinião dos seus seguidores quanto ao processo eleitoral.

Até ao presente, as investigações da Maka Angola têm permitido denunciar os abusos do regime político no país e também ocasionado processos judiciais em Angola, Portugal e até nos Estados Unidos. O conteúdo da Maka Angola acaba por se repercutir não apenas na imprensa alternativa nacional e internacional, mas também na imprensa tradicional mainstream (Publico.pt; DW/ Deutsche Welle News; The Fifth Column News) ${ }^{7}$ e ainda em organizações que defendem a liberdade de imprensa como causa: Index on Censorship, Commitee to Protect Journalists e Corruption Watch ${ }^{8}$. 


\section{A Maka Angola : contribuição para um espaço público plural e democrático?}

A questão que nos importa colocar, a partir da plataforma Maka Angola, é em que medida os espaços públicos mediatizados e alternativos, que surgem nas redes digitais, concorrem para práticas de partilha democráticas ou, em suma, para a democracia. Sabemos que o espaço público democrático requer condições de existência, como sejam a liberdade de expressão e de imprensa, bem como a livre circulação e divulgação de informações que favoreçam o debate público crítico e a formulação dos problemas sociais tornados públicos, assim como a constituição de públicos informados. Examinemos, pois, à luz do caso Maka Angola, como estas condições advêm no contexto angolano.

Em Angola, a liberdade de expressão é limitada. Ora, face ao controlo por parte do Estado sobre as notícias e sobre a possibilidade dos cidadãos se informarem livremente, a Maka Angola contribui para instaurar um espaço de comunicação democrática, na medida em que propõe temas, que habitualmente não ganham difusão e visibilidade nos média de massa, para reflexão dos cidadãos. Refira-se, para elucidar, que um problema de corrupção angolana, que ocorreu com o então vice-presidente da República de Angola, Manuel Vicente, que foi acusado formalmente de corrupção ativa, branqueamento de capitais e falsificação de documentos em Portugal, em 2016 ${ }^{9}$, foi colocado na plataforma a partir de denúncias públicas, tendo vindo a culminar com a sua arguição em processo penal.

27 A Maka Angola fomenta uma cultura de denúncia mediante um médium não subjugado ao poder político e, por meio de uma discussão mediatizada livre, cria condições ao exercício da liberdade de expressão, da crítica e da formação de opiniões, alcançando aspetos constitutivos do espaço público democrático, nomeadamente, a formação de opiniões e vontades e a constituição de públicos. Aliás, na medida em que a plataforma utiliza o website e os média digitais sociais para que os cidadãos angolanos e internacionais acedam às informações problemáticas e também para que encontrem meios disponíveis para emitir opiniões, através de seus comentários, fora da agenda dos média convencionais, podendo mesmo divergir do conteúdo da Maka Angola, é de um espaço público de diálogo e debate que se trata. E embora favoreça os designados "públicos fracos" que, para Fraser (1990:75), são aqueles "cuja prática deliberativa consiste em formação da opinião e não tomada de decisão", a Maka Angola contribui para o empoderamento dos cidadãos. Ela cria uma oportunidade de discutir a corrupção, a impunidade, as relações desiguais de poder e o cerceamento dos direitos de expressão. Esta contribuição vai de encontro ao que Fraser (1990) refere como necessidade de empoderar os chamados "públicos subalternos", de engajá-los em espaços públicos de discussão crítica onde eles possam ser capazes de criar os seus próprios "contradiscursos" ou "contra narrativas" a partir das suas identidades e percepções do que é a democracia (Fraser, 1990 :123).

\section{A comunicação digital e as suas repercussões sociais}

Com os novos movimentos sociais que se iniciaram nas redes digitais (Occupy Wall Street, Movimiento 15-M ou Indignados, Que se Lixe a Troika, \#Elenão, etc.), os média sociais tiveram 
uma função importante ao ampliarem a circulação e disseminação das informações e apelos à mobilização pública, ao criarem espaços para expressão das opiniões e ao favorecerem a participação e a articulação direta dos agentes destes movimentos (Bennett e Segerberg, 2012; Tufte, 2013; Babo e Silva, 217). Thomas Tufte (2013, 2017) argumenta que espontaneidade como estes movimentos estão a ser engendrados nas redes e transpostos para o meio offline, dilatam a comunicação para o desenvolvimento, mediante um envolvimento mais significativo dos cidadãos do que a comunicação concebida e realizada pelas instituições na designada indústria do desenvolvimento, como as organizações multilaterais e ONG. Nesta medida, o autor assinala que os novos média digitais, no âmbito da comunicação para o desenvolvimento, tem vindo a abrir "espaços para críticas sociais e facilitando novas formas de mobilização social" (Tufte, $2013: 63)^{10}$, através dos quais os atores assumem papéis mais participativos como produtores de conteúdos para os média, como é o caso de jornalistas cidadãos e blogueiros, e conquistam visibilidade, voz e poder no espaço público.

Nick Couldry, na sua obra Why Voice Matters (2010), aprofunda a relação entre visibilidade, voz e poder, dedicando-se a perceber o papel de uma 'sociologia da voz' e a compreender como o paradigma neoliberal repercutiu numa narrativa de exclusão as histórias que os indivíduos têm sobre as sua próprias vidas, reduzindo, desta forma, o seu poder. Couldry (2010:15) argumenta que é possível conferir uma outra narrativa que seja capaz de reestabelecer "uma capacidade fundamental dos seres humanos e seu exercício crucial para a vida, independentemente das condições sociais que estas pessoas tenham". A aposta de Couldry (2010), para incluir vozes marginalizadas no espaço público, passa por criar narrativas coletivas maiores que as individuais, onde os média online representam uma importante contribuição para a construção de narrativas subalternas da voz. Também Waltz (2005) considera que os media alternativos, de carácter ativista, podem fornecer tipos de informação e temas que os média tradicionais não exploram e não consideram parte da sua agenda, como são exemplos peças jornalísticas de cariz investigativo. Waltz (2005:4) alega que, em momentos de conflito ou convulsão social, "eles fornecem uma contra-narrativa àquela apresentada pelos média tradicionais, mas essa narrativa pode ser expressa de muitas maneiras diferentes, dependendo da época".

Mas também é relevante considerar os pontos de vista de autores que advogam que a noção de participação cívica não é absolutamente potenciada pelos meios digitais, mas, ao contrário, é relativizada. Para Pradip Thomas (2014:10), o projeto de participação dos cidadãos e das decisões que lhes dizem respeito foi sendo limitado mesmo com advento dos meios digitais, precisamente porque não confere aos cidadãos que interagem com os meios digitais, sejam eles produtores ou consumidores, a oportunidade de participar com "exercício de plena liberdade". Thomas cita como exemplo o fenómeno do slackativismo", nas redes sociais, que incentiva as pessoas a uma participação superficial, contribuindo com um 'click' em pesquisas de opinião e questões online, algo que, segundo Thomas (2014:10) "não permite um envolvimento efetivo com os problemas reais que elas enfrentam". Com efeito, Evgeni Morozov (2011:218) sustentou a ideia de utopia e de não participação nas redes, argumentando que a disponibilidade de ferramentas para o ativismo online é contraproducente, pois integra o sistema neoliberal em vigor e distrai os ativistas das formas de envolvimento necessárias para alcançarem uma mudança política significativa ou mesmo para influenciar processos democráticos. Para Morozov (2011), a ação conectada constitui uma ameaça ao ativismo convencional fora das redes, criando a ilusão de ação coletiva coordenada pelos cidadãos, o que, de facto, não se concretizará. Da 
mesma forma, esta ação conectada também é reducionista quando circunscreve o ativismo às formas de engajamento meramente simbólicas, ou sem efetividade, pois ignora as questões de raiz da participação, onde estão o poder e os mecanismos de empoderamento.

31 A questão que se coloca, de seguida, a partir do caso Maka Angola, é se existem efetivas contribuições dos média alternativos e do netativismo na ação coletiva e pública, e se esta plataforma de comunicação, especialmente no contexto angolano, suscita condições e efeitos de natureza democrática.

\section{Netativismo e média alternativos}

O netativismo pode ser compreendido, de acordo com Di Felice (2013b ; 2017), no contexto de uma nova ecologia de ações colaborativas entre: "pessoas, circuitos informativos, dispositivos, redes sociais digitais, territorialidades informativas que se expandem reticular e conectivamente" (Di Felice, 2017 :186). Em termos de uma conceptualização do netativismo, Di Felice (2017:134-135) traça o seu percurso histórico marcado por três principais momentos: inicialmente distingue-se por incorporar características que conferem visibilidade e notoriedade a causas e grupos ; depois, em meados nos anos 90, é marcado por uma lógica de "conflitualidade atópica", ocupando diversas territorialidades em simultâneo; na atualidade, é assinalado por "formas reticulares autónomas e colaborativas de ativismo" (Di Felice, 2017 :135).

33 Também Atton (2002) já assinalara a capacidade dos média eletrónicos alternativos gerarem discussões e debates entre os participantes e um contexto de mudança social onde desejam construir agendas e desenvolver opinião. Seguindo-se a intenção de alcançar um número amplo de participantes e de incentivar a educação e comunicação destes, em especial daqueles potencialmente em conflito, onde este espaço alternativo de média estará mais disponível a uma ampla gama de vozes e opiniões. Por sua vez, Bailey, Cammaerts \& Carpentier (2007:11) abordam o conceito de meios alternativos a partir de uma relação íntima com o serviço às comunidades, onde grupos que partilham identidades culturais e geográficas similares conseguem estabelecer vínculos coparticipativos visando um "bem-comum". Estes meios podem, assim, conferir às comunidades o empoderamento de grupos ou populações, algo que se consegue quando há participação na coprodução dos conteúdos e sua organização de forma contínua.

34 A partir deste quadro de referência, interessa-nos responder à questão seguinte : de que modo a plataforma Maka Angola constitui um meio alternativo e de netativismo no espaço público angolano e qual a sua contribuição ou consequências?

\section{Maka Angola : contributo à visibilidade}

35 A partir da formulação de problemas sociais, assim tornados públicos, a Maka Angola usa a comunicação para gerar públicos mais participativos que coproduzem informação. Acaba, assim, por estimular a mobilização e a mudança social que se iniciam a partir da informação e comunicação e culminam com a informação voltada para a ação ou, como observa Atton (2002 :156), para uma "ação da ação". Do ponto de vista do ativismo em rede, a plataforma instaura um novo tipo de "ecologia conectiva" (Di Felice, 2013a :13) onde os cidadãos interagem com os seus pares e com outros "actantes" (Di Felice, 2013a :9), por meio de dispositivos electrónicos e circuitos informativos. Deste modo, 
constitui um espaço de participação e mudança social quando, ao propagar informação que normalmente é censurada pelo Estado, promove a discussão crítica de ideias e uma participação cidadã.

A Maka Angola, ao suscitar espaços de discussão e ao lançar tópicos de interesse público nas redes sociais Facebook e Twitter, estimula a experimentação por parte dos seus públicos e potencia que eles 'sejam e façam', minimizando os efeitos das relações desequilibradas de poder (Atton, $2002: 153$; Fucks, 2017). Neste âmbito, também tem potencial para reforçar as identidades comunitárias, onde as questões partilhadas são questões resolvidas comummente (Bailey, Cammaerts \& Carpentier, $2007: 12$ ). Ao mesmo tempo e em termos do netativismo, a Maka Angola reúne algumas das "características da forma de conflitualidade netativista" que Di Felice (2017:185-191) enumera. A primeira delas é o 'anonimato', importante no engajamento naquele contexto de repressão social. A segunda, o facto de a plataforma não configurar uma necessária identidade política daquele grupo de participantes, ou não requerer hierarquias formais, antes, porém, facultar a interação da diversidade e pluralidade; no caso, entre angolanos e nãoangolanos, simpatizantes da política vigente no país e opositores, sem a necessidade de convocar lideranças. Como resultado, a Maka Angola demonstra ser o ambiente colaborativo à troca e debate de ideias, na lógica de um "netativismo frontal", com efeitos no meio online (Di Felice, 2017 :185). A terceira característica é a "passagem de práticas e de estratégias políticas ao princípio da ação emergente" (Di Felice, 2017 :185) que, no caso da Maka Angola, se expressa pelos angolanos buscarem a discussão dos seus problemas pela via participativa no ambiente online.

características do netativismo defendidas por Di Felice (2017 :189-191) não se aplicam ao caso Maka Angola : a primeira, é "a recusa do diálogo com as instituições", em que o autor constata uma postura de rotura da ação netativista com organizações formalmente constituídas, enquanto a Maka Angola busca o diálogo entre distintas correntes de ideias e apela a todos, inclusivamente às instituições, a participarem no seu site e usa igualmente canais mais interativos como o Facebook, Youtube, Instagram e Twitter. A segunda, é "a ausência de uma ideologia comum" entre os participantes (Di Felice, 2017 :189) e ainda não haver uma bandeira e haver uma autonomia individual de pensamento. Ora, a Maka Angola "ostenta a bandeira" e proclama no seu slogan : Em defesa da democracia, contra a corrupção, procurando ser um espaço de partilha onde o problema da corrupção e a ideia de democracia podem ser refletidas e discutidas.

Em suma, a plataforma Maka Angola desencadeia alguns aspetos da lógica netativista e, sobretudo, cria condições de visibilidade a problemas que, de outro modo, poderiam não adquirir configuração pública. Daqui advém como consequência a formação de um espaço público alternativo de caráter democrático.

\section{Considerações finais}

Em sociedades democráticas existem condições de liberdade de informação e expressão, e a comunicação mediática e, sobretudo, o jornalismo de investigação concorrem para a formação de públicos convocados para um debate crítico e participativo. Não discutindo aqui o facto de os média de massa não instaurarem, usualmente, condições para uma discussão crítica, e de os média digitais serem o lugar de um jornalismo cidadão e participativo e, simultaneamente, de disseminação de opiniões particulares não 
fundamentadas ou mesmo de falsidades. Porém, em Angola, onde não existem meios de comunicação tradicionais (imprensa escrita, rádio e televisão) livres, e onde não há um acesso livre e generalizado à informação, não estão criadas condições para um espaço público democrático. Por isso, ao considerarmos que a Maka Angola não é somente um meio alternativo, que instaura um espaço de informação e debate onde emerge uma pluralidade de vozes, mas é também um dispositivo de expressão e ação com características de netativismo, entendemos que ela institui um espaço público alternativo que, por sua vez, cria condições que contribuem para a constituição de uma esfera pública democrática na sociedade angolana.

Em rigor, as condições para a institucionalização de um espaço público democrático, que garanta a publicitação dos assuntos públicos, respeitam uma cultura democrática assente nos princípios ético-jurídicos do Estado de Direito. Ou seja, existem diversas condições que são necessárias e que vão da liberdade de expressão e comunicação, às instituições e cultura democráticas e às práticas de uma sociedade. Ora, a Maka Angola efetiva uma possibilidade e a abertura a condições de uma esfera pública democrática quando, por um lado, torna públicos temas e problemas silenciados pelo Estado e, por outro lado, procura dar voz a atores arredados do espaço público e suscita o debate crítico. Esta emergência pública de assuntos e vozes faz com que a Maka Angola favoreça o empoderamento de indivíduos ou de populações, o que tem efeitos comunicacionais, sociais e políticos. A plataforma também contribui para colocar em diálogo públicos diferenciados, fomentando uma cultura de discussão e participativa.

41 Fica por analisar a influência que a plataforma alcança no meio offline, relativamente a formas de atuação engendradas online dos atores-utilizadores e que podem prosseguir no meio offline, rumo a práticas de comunicação livres e a mudanças sociais. Isto responderia parcialmente às críticas e reservas levantadas por autores críticos dos meios digitais (Thomas, Morozov e outros) quanto a estes servirem como meio de participação, empoderamento e mudança social. Não tendo havido ocasião, no âmbito deste texto, para analisar a questão das redes digitais serem o lugar do ativismo em rede e, ao mesmo tempo, onde vigora a individualização, a dispersão e o não comprometimento (Babo, 2018), é um facto que os novos média digitais e, no caso, a plataforma Maka Angola, instauram espaços públicos plurais e alternativos, nos quais os indivíduos conquistam visibilidade, voz e novas formas de poder e mobilização pública.

A Maka Angola, ao difundir publicamente problemas da sociedade angolana, cria condições para a discussão destes e para a formação de públicos, tendo como efeito contribuir para mudanças sociais e políticas.

\section{BIBLIOGRAFIA}

Atton, C. (2002). Alternative media, London : Sage

Babo, I. e Silva, C. T. (2017). Social Networks and Civic Mobilizations (Portugal, 2012), Academic

Journal of Interdisciplinary Studies, vol 6, no2 S1, pp. 49-57. 
Babo, I. (2018). Média, tempo e memória, Revista Vista nº 2, Sopcom, 77-95.

Bailey, O. G., Cammaert, B., \& Carpentier, N. (2007). Understanding alternative media, London : McGraw-Hill Education

Bennett, W. L. e Segerberg, A. (2012). The logic of connective action, Information, Communication \& Society, $15: 5,739-768$.

Castells, M. (2000). Sociedade em Rede, São Paulo : Paz e Terra.

Castells, M. (2007). Communication, power and counter-power in the network society. International journal of communication, 1(1), 29, 238-266.

Couldry, N. (2010). Why voice matters: Culture and politics after neoliberalism, London : Sage.

Di Felice, M. (2012). Netativismo : novos aspectos da opinião pública em contextos digitais, Revista Famecos, v.19, n.1, Porto Alegre, 27-45.

Di Felice, M. (2013a). Net-ativismo e ecologia da ação em contextos reticulares. ContemporâneaRevista de Comunicação e Cultura, 11(2), 267-283.

Di Felice, M. (2013b). Ser redes : o formismo digital dos movimentos net-ativistas, Matrizes, vol. 7, n. 2, São Paulo : USP, 49-71.

Di Felice, M. (2017). Net-ativismo : da ação social para o ato conectivo. São Paulo : Editora Paulus.

Fenton, N. (2010). New media, old news : Journalism and democracy in the digital age. Sage Publications.

Fraser, N. (1990). Rethinking the public sphere : A contribution to the critique of actually existing democracy. Social Text, no 25/26, 56-80.

Fraser, N. (2003). Repenser l'espace public, in Renault, E. e Sintomer, Y. (dir.) Où en est la théorie critique? Paris : La Découverte, 103-134.

Fuchs, C. (2017). Social media : A critical introduction, London : Sage.

Habermas, J. (1986 [1962]). L'Espace Public. Archéologie de la Publicité comme dimension constitutive de la société bourgeoise, Paris : Payot.

Habermas, J. (1988 [1985]). Le discours philosophique de la Modernité, Paris : Gallimard.

Habermas, J. (1992). « "L'espace public", 30 ans après ", Quaderni, 18, 161-191.

Morozov, E. (2011). The Net Delusion : The Dark Side of Internet Freedom. New York : Public Affairs.

Silveirinha, M. J. (2004). Identidades, media e política : o espaço comunicacional nas democracias liberais. Livros Horizonte.

Thomas, P. N. (2014). Development communication and social change in historical context. The handbook of development communication and social change, 5-19.

Tufte, T. (2013). O renascimento da Comunicação para a transformação social-Redefinindo a disciplina e a prática depois da 'Primavera Árabe'. Intercom-Revista Brasileira de Ciências da Comunicação, 36(2), 61-90.

Tufte, T. (2017). Communication and Social Change : A Citizen Perspective, Cambridge : Polity Waltz, M. (2005). Alternative and activist media, Edinburgh : University Press. 


\section{NOTAS}

1. Em Angola, há uma transição ao nível da presidência da República, desde as eleições de agosto de 2017, e, mais recentemente, desde setembro de 2018, ao nível da presidência do partido no poder, Movimento Popular para a Libertação de Angola (MPLA). Estes dois processos eleitorais marcaram o fim da presidência do país de José Eduardo dos Santos (de 1979 a 2017) e, posteriormente, do partido no poder, MPLA, que governa Angola desde a independência (1975). João Lourenço é o atual presidente de Angola (desde 2017) e do MPLA (desde 2018).

2. Disponível em https://www.theguardian.com/world/2015/mar/18/angola-journalist-prisonrafael-marques-de-morais

https://www.theguardian.com/world/2015/oct/13/angola-repression-generates-more-dissentpolitics-mpla

http://www.amnesty.org/en/countries/africa/angola/report-angola

3. "J'ai évalué de façon trop pessimiste la capacité de résistance, et surtout le potentiel critique d'un public de masse pluraliste et largement différencié, qui déborde les frontières de classe dans ses habitudes culturelles“ (Habermas, 1992 :174).

4. "Les associations à l'origine de la formation d'opinions, autour desquelles peuvent se cristalliser des espaces publics autonomes, bénéficient d'une position éminente dans la société civile" (Habermas, $1992: 186)$.

5. https://www.makaangola.org/sobre/

6. Disponível em http://www.makaangola.org/seguranca-digital/

7. https://www.dw.com/pt-002/maka-angola/t-19555790

https://thefifthcolumnnews.com/tag/maka-angola/

8. http://www.indexoncensorship.org/tag/maka-angola/

https://cpj.org/2016/12/in-angola-two-journalists-charged-over-report-on-c.php

https://cpj.org/tags/Maka-Angola

https://www.corruptionwatch.org.za/tag/maka-angola/

9. Caso que ficou conhecido como Operação Fizz. Disponível em observador.pt/opiniao/oextraordinario-desfecho-do-caso-manuel-vicente

10. Para Tufte (2013:65) a ação cívica "é a manifestação ativa dos cidadãos como requerentes de desenvolvimento" e é fruto de um processo pelo qual a identidade e a ação se unem na intervenção comunicativa para promover mudança social.

11. Termo que apareceu na obra de Evgeny Morozov (2011), intitulada The Net of Desilusion: the dark side of Internet Freedom, associado ao desvio da tentativa de ativismo social na internet. 0 Slackativismo é caracterizado pelo engajamento superficial dos utilizadores em causas que tornam ineficazes muitas intervenções pró-participação e cívicas que não tocam nas questões de fundo, como o poder e o empoderamento.

\section{RESUMOS}

Nous voulons poser quelques questions sur les conditions d'existence d'un espace public de communication dans le contexte d'une société en voie de démocratisation. De ce fait, on se propose à analyser le cas de la plate-forme de communication Maka Angola, en examinant son 
rôle dans l'espace public angolais, dans la perspective de la communication démocratique et de l'émancipation des populations. Pour cela, les notions d'espace public, d'activisme en réseau ou de net-activisme et de médias alternatifs sont mobilisées. On remarque et discute que Maka Angola est en train de contribuer à stimuler l'espace public angolais, dans la mesure où elle soulève la formulation et la publicisation de problèmes publics, elle déclenche un ample débat critique et encourage la prise en compte de voix marginalisées, en favorisant ainsi l'émancipation et pouvant cet effet être compris du point de vue de la communication pour le développement. Cela nous permet d'évaluer le rôle des nouveaux médias numériques dans l'émergence d'espaces publics pluriels dans lesquels les individus acquièrent visibilité, voix, pouvoir et de nouvelles formes de mobilisation.

This work aims to explore some questions about the conditions of existence of a public sphere in the context of a society in the process of democratisation. The analysis we propose is the case study Maka Angola, a digital communication platform, seeking to examine the role it plays in Angolan public sphere in the perspective of democratic communication and the population's empowerment. For this aim, we discuss the theoretical notions of Public Sphere, as well as the concepts of net activism and alternative media. Through this discussion, we verify that Maka Angola contributes to revitalise the Angolan public sphere, insofar as it raises the local public problems and supports its awareness, nationally. Maka Angola also triggers the critical discussion among the individuals and supports the inclusion of marginalized voices, advancing the population's empowerment. In the light of communication for development, these effects allows us to consider the role of the new digital media in the establishment of public spheres in which individuals gain visibility, voice, power and new forms of mobilisation.

Pretende-se explorar algumas questões sobre as condições de existência de um espaço público de comunicação no contexto de uma sociedade em vias de democratização. Para tal, a análise a que nos propomos é ao caso da plataforma de comunicação Maka Angola, examinando o papel que esta desempenha no espaço público angolano, na perspetiva da comunicação democrática e do empoderamento de populações. Para esse efeito, mobilizam-se as noções de Espaço Público, ativismo em rede ou netativismo, e média alternativos. Discute-se e constata-se que a Maka Angola contribui para estimular o espaço público angolano, na medida em que suscita a formulação e publicitação de problemas públicos, desencadeia um debate crítico alargado e incentiva a inclusão de vozes marginalizadas, favorecendo o empoderamento e podendo este efeito ser entendido na ótica da comunicação para o desenvolvimento. Isso permite encarar o papel dos novos média digitais na emergência de espaços públicos plurais nos quais os indivíduos conquistam visibilidade, voz, poder e novas formas de mobilização.

\section{ÍNDICE}

Keywords: public sphere, digital media, alternative media, net activism

Palavras-chave: espaço público, média digitais, média alternativos, netativismo

Mots-clés: espace public, médias numériques, médias alternatifs, net-activisme

\section{AUTORES}

\section{CÁSSIA AYRES}

Université de Porto, Portugal 


\section{ISABEL BABO}

Université de Porto, Portugal 